Article

\title{
A Running Start or a Clean Slate? How a History of Cooperation Affects the Ability of Cities to Cooperate on Environmental Governance
}

\author{
Rui Mu ${ }^{1, *(\mathbb{D})}$ and Wouter Spekkink ${ }^{2}$ \\ 1 Faculty of Humanities and Social Sciences, Dalian University of Technology, Dalian 116024, China \\ 2 Sustainable Consumption Institute, The University of Manchester, Manchester M13 9PL, UK; \\ wouter.spekkink@manchester.ac.uk \\ * Correspondence: ruimu@dlut.edu.cn
}

Received: 27 April 2018; Accepted: 8 June 2018; Published: 11 June 2018

\begin{abstract}
Since 2013, the Chinese central government has pushed cooperation on environmental governance in Urban Agglomerations (UAs). In some of these UAs, cities have previously been developing environmental governance activities autonomously, in the absence of inter-city cooperation, while on others, spontaneous cooperation has previously taken place. These differences in historical context provide us with an opportunity to study, in a comparative way, how a history of cooperation influences the effectiveness of inter-city cooperation on environmental governance. Our approach to carrying out this comparison is to reconstruct the trajectories of events that describe the evolution of environmental governance in two UAs (Beijing-Tianjin-Hebei and Yangtze River Delta), covering the period from the early 90s to 2016. The main findings of this study are that the trajectory of environmental governance in a historical context of prior spontaneous cooperation is more effective in achieving goal intertwinement than that in a historical context of no prior cooperation; and that informal forms of cooperation, along with decentralized coordination by local actors, are critical and more influential in bringing about more effective cooperation. On the other hand, in a historical context of no prior cooperation there is an opportunity to design a cooperative structure from scratch; in this process attention should be paid to the creation of an equal playing ground, with balanced costs and benefits for all partners. By contrast, cooperation on environmental governance in a context where there is a history of spontaneous cooperation the central government can still play a role in the further facilitation of cooperation.
\end{abstract}

Keywords: environmental governance; cooperation; historical context; urban agglomeration

\section{Introduction}

China's environmental pollution is one of the most pressing challenges to emerge from the country's rapid urbanization and industrialization [1]. Its economic rise, in which GDP grew on average 10 percent each year for more than a decade, has come at the expense of its environment [2]. China is one of the world's largest sources of carbon emissions; the air quality of many of its major cities fails to meet international health standards; and severe water contamination and scarcity have compounded land deterioration [3].

It is against this background that the Xi's government that came to power in 2013 is making much of its commitment to "joined-up working", "transboundary cooperation" and "inter-jurisdictional coordination" in environmental governance, by which it means horizontal integration of environmental policies, industrial layout coordination across jurisdictions, and resource gathering from multiple stakeholders $[4,5]$. The first step by which China is pursuing this commitment was to establish twenty 
Urban Agglomerations (UAs) in its National Plan for New Urbanization in 2013 [4]. These UAs are clusters of cities that consist of one or two core cities and their geographically adjacent areas [6]. The main purpose of the establishment of UAs is to urge cities within agglomerations to jointly improve their environmental quality. The second step is to deploy the Plan for Environmental Governance System Construction, which aims to improve the rule of law and regulatory policies of governmental organizations and to strengthen synergetic law enforcement of the agglomerations [5]. In both steps, the Chinese central government promotes cooperation on environmental governance between cities, in the hope that, through cooperation, city governments can tackle environmental challenges that they cannot solve alone $[7,8]$.

Indeed, the twenty UAs established in the process are not all alike. A key difference is the extent to which cities within UAs have previously cooperated on inter-city environmental affairs. In some of the UAs set up through the state government initiative, cities have primarily developed environmental governance activities autonomously, while in other UAs inter-city cooperation has already taken place spontaneously $[6,9,10]$. In this article, we focus specifically on these differences in the history of cooperation of UAs. Several conceptual frameworks point to prior cooperation as a key determinant of the successful establishment of cooperation [11-13]. There are indeed other historical conditions of UAs that co-determine the effectiveness of cooperation in the present (e.g., incompatible or conflicting bureaucratic cultures, power imbalances, differences in the degree of environmental pollution between cities), but our intention is to study the influence of differences in the history of cooperation in elaborate detail, with attention for the events through which this influence plays out over time. This would not be feasible if other factors were examined in detail as well. However, in our concluding section we offer concrete suggestions of how the interaction between the history of cooperation and other historical conditions might be examined.

Our overall proposition is that cooperation on environmental governance will take different forms, depending on the history of cooperation, and lead to different results in terms of the effectiveness of cooperation. In this study, we use "goal intertwinement" as a criterion of effectiveness of cooperation, which refers to the extent to which the outcome of cooperation intertwines diverging goals of actors involved and reduces or compensates costs and negative side-effects of cooperation [14]. We therefore picked two contrasting cases for our study: one case in which the cities were able to build on the legacy of prior, spontaneously developed cooperation on environmental governance (the Yangtze River Delta [YRD] agglomeration), and a second case in which cities previously developed their policies on environmental governance autonomously (the Beijing-Tianjin-Hebei [BTH] agglomeration). Our examination of these two contrasting cases was guided by a set of propositions that we derived from the conceptual discussion offered in Section 2. We formulated the following overall research question: how effective is cooperation in harmonizing city-level environmental governance activities when there is a history of past cooperation, compared with a historical context where prior cooperation is absent?

For both case studies, our overall strategy was to reconstruct the trajectories of events that describe the evolution of environmental governance in the UAs, covering the period from the early 90 s to 2016. These trajectories consist of events and relationships between the events. We distinguished between two broad categories of events. The first category concerns the autonomous actions that city governments in China take to put into place, monitor, and enforce legislative frameworks and policies for environmental governance. The second category includes joint actions, that is, actions towards environmental governance that city governments take cooperatively $[14,15]$. In this paper, we distinguish two further sub-types of joint actions. The first sub-type concerns formal joint actions, such as the establishment of inter-local policies, regulations, and agreements that the cities use as broader frameworks for their own legislative activities. The second sub-type concerns joint actions of an informal nature, where alignment of the actions of different city governments takes place through the informal mechanisms between leaders of city governments, without necessarily leading to formalized inter-city rules, norms, and/or agreements. The relationships between events indicate how events condition each other. All events that we considered are purposeful activities of actors, whom respond 
to conditions raised in events that happened earlier, and at the same time shape the conditions under which future activities unfold (cf. Spekkink and Boons [16]). Trajectories of events are sequences of events related in this way, and in this paper they describe the evolution of environmental governance in the BTH and YRD UAs. In doing so, we paid special attention to the ways in which joint and autonomous actions influence each other. The overarching research approach that we used to construct and analyze trajectories of events is Event Sequence Analysis (ESA, see [16,17]). In the next section, we provide the conceptual basis for our work, in which our categorization of types of events is rooted. In Section 3, we outline our research design, and offer a further introduction into our two cases. In Section 4, we present our findings, and based on our findings, we offer answers to our research questions and draw implications for further research in Section 5.

\section{Conceptual Framework}

In this section, we distinguish two broad categories of events, autonomous actions and joint actions in environmental governance. All events refer to activities that are purposefully carried out by actors, which in this study are organizations at different levels of government, as well as elected officials and non-governmental organizations (NGOs) involved in environmental governance processes. The autonomous actions are those events that capture activities by actors from a single city. By contrast, the joint actions are those events that capture activities carried out by actors from multiple cities within an UA. After defining our event types in more detail, we bring forward propositions to guide our empirical research.

\subsection{Autonomous Action in Environmental Governance}

Environmental governance can be broadly defined as "interventions aiming at changes in environment-related incentives, knowledge, institutions, decision making, and behaviors" [18], or as "the establishment, reaffirmation or change of institutions to resolve conflicts over environmental resources" [19]. In combination, these two definitions draw attention to interventions that involve the establishment, maintenance, and transformation of institutions designed to constrain and guide human behavior [20-22] relevant to environmental impact. Often, these institutions take the form of environmental legislation, which is a fundamental instrument to hold public and private entities accountable for environmental harm [23]. Rules, regulations, and policies are among the primary resources that governmental actors typically mobilize for environmental protection. Legislative and policy actions are therefore one type of action that we distinguish as an event, and it includes the initiation, formulation, and adaptation of legal rules for environmental protection by city-level governmental organizations.

Legislative frameworks need to be monitored and enforced to be effective, which is why we distinguish monitoring and enforcement actions (e.g., environmental inspections, sanctions) as a second type of event relevant to environmental governance. Enforcement itself can be problematic. This is especially true when both monitoring and enforcement functions are performed by front-line public officials who may choose to allow their enforcement activities to be influenced by bribes, the aversion of high workloads, and avoidance of unpleasant confrontations with local leaders [24,25]. For example, Liu et al. [1] show that the municipal governments in China, which are under serious pressure from the center to perform economically, may tolerate or even encourage entrepreneurial behavior that generates pollution. Local environmental protection bureaus, which politically and administratively rank lower than municipal governments exert little oversight and enforcement power over polluting enterprises. McAllister [23] shows that in some circumstances environmental rule of law fails because the regulatory agency staffs are poorly paid, creating conditions conducive to corruption and lacking incentives to do serious inspections. Only when the front-line officials are willing to carry out serious enforcement activities and issue sanctions upon detection of violations, can the effectiveness of legal rules be ensured. 
Political attention and scrutiny may act as a stimulant for regulatory agencies to act appropriately [1,26,27]. In this study, political attention and scrutiny from elected officials may be understood as the "appropriate external cues" [28] that motivate regulatory agencies to respect rule of law, for example by increasing the political risks associated with leniency towards polluting enterprises. Elected officials may visit enforcement agencies to incentivize environmental inspections; they may also occasionally bypass enforcement agencies to carry out their own inspections, putting pressure on the enforcement agencies to make sure no missteps are made during their more regular inspections. Our conceptual scope thus also includes political actions that express the level of support and attention obtained from elected officials in implementing environmental policies and in conducting enforcement activities. Support from top politicians may foreclose back channels, legitimate inspection actions, and secure enforcement funding.

\subsection{Joint Action in Environmental Governance}

Joint actions differ from autonomous ones in the sense that they involve multiple actors affiliated to different cities in the agglomeration. These actions typically involve the establishment of inter-city information-sharing channels and the formulation of common goals and joint strategies/plans for environmental governance. We expect that through establishing common goals, joint visions and communication mechanisms in joint actions, the cities in UAs are incentivized to carry out autonomous actions more seriously. In this study, we distinguish two sub-types of joint action: formal joint action and informal joint action.

First, city governments may jointly define formal rules and norms to establish an overarching framework that guides the activities of individual cities [29,30], incentivizing strategies that help city governments to attain collective benefits that are difficult to achieve when each city acts on its own accord [31-33]. These formal rules and norms may take the form of joint policy frameworks, inter-local agreements and contracts [34,35]. Formal joint actions do not only concern the establishment of joint rules and norms. City governments may also establish joint organizations (e.g., the establishment of associations or coalitions), develop joint projects, plans, and strategies, and/or establish information-sharing channels [36].

Second, informal channels and loosely coupled coordination systems can also play an important role in the practice of environmental governance in China [37]. Informal channels, based on personal relationships between leaders of different city governments, are the most direct contributors to cooperation issues. In addition to personal visits and dialogues, informal channels may take the form of loosely coupled coordination systems [38], such as meetings and forums among the leaders of city governments. These systems have no legal standing, and are highly problem-oriented, pragmatic, flexible, and adaptive. These platforms meet irregularly, on the basis of need, and have no board of directors or employees of their own. Yet the importance and influence of these systems are pervasive and persistent. They are major vehicles for the development and maintenance of social capital that ties city governments together. Social capital refers to features of social organization such as networks, norms, and social trust that facilitate collective action [39-43]. By building up relationships of trust and norms of reciprocity, cooperation becomes easier because of the reduced time and effort required for bargaining and negotiation [44,45]. Table 1 offers a summary overview of the types of events we focus upon. 
Table 1. Summary overview of types of events.

\begin{tabular}{ccl}
\hline Action Category & \multicolumn{1}{c}{ Action Type } & \multicolumn{1}{c}{ Description } \\
\hline \multirow{3}{*}{$\begin{array}{c}\text { Autonomous } \\
\text { actions }\end{array}$} & $\begin{array}{c}\text { Legislative and policy actions } \\
\text { (LPA) }\end{array}$ & $\begin{array}{l}\text { Establishment, adaptation or termination of legal prescriptions (including laws, } \\
\text { regulations, policies, plans, directives, and formal procedures. }\end{array}$ \\
\cline { 2 - 3 } & $\begin{array}{c}\text { Monitoring and enforcement } \\
\text { actions (MEA) }\end{array}$ & $\begin{array}{l}\text { Carrying out environmental inspections and carrying out sanctions when the } \\
\text { inspected entity breaks environmental regulations. }\end{array}$ \\
\cline { 2 - 3 } Political actions (PA) & $\begin{array}{l}\text { Political leaders personally carry out surveys or inspections, or political leaders } \\
\text { make political statements to incentivize environmental protection. }\end{array}$ \\
\hline Formal joint actions (FJA) & $\begin{array}{l}\text { The establishment of formal inter-local frameworks and agreements, } \\
\text { the establishment of supra-local organizations, associations and/or coalitions, } \\
\text { the development of joint projects, plans and programs, and the establishment of } \\
\text { information-sharing channels and common goals and visions. }\end{array}$ \\
\cline { 2 - 3 } & Informal joint actions (IJA) & Meetings among major local leaders, and informal oral agreements. \\
\hline
\end{tabular}

\subsection{The Effectiveness of Cooperation on Environmental Governance}

Our central research question is about the comparative effectiveness of cooperation on environmental governance when cooperation has already taken place spontaneously in the past, versus a context in which this history of cooperation is absent. We conceptualize these two situations as two different trajectories of environmental governance, where the trajectories are formed by events and their relationships. The events capture the various types of actions that occur in the trajectories, and to qualify these events, we use the typology we developed in Sections 2.1 and 2.2. The relationships between the events capture the ways in which events condition each other: in taking autonomous or joint actions, the actors involved may respond to conditions created in earlier events. Whenever this occurs, we say that these events are related. Trajectories are the chains of events that are formed in this way.

In trajectories of environmental governance in the presence of a history of spontaneous cooperation we will thus observe cooperative action earlier on compared with trajectories of environmental governance where a history of cooperation is absent. Based on insights from existing literature, there are several other differences that we can expect to observe in the two different types of trajectories as a result of this, and we propose that some of these differences are relevant to the comparative effectiveness of cooperation in the two types of trajectories. In this section, we discuss a few of these differences, organizing our discussion around propositions. We close the section with two main propositions on the comparative effectiveness of cooperation (1) when there already is a history of cooperation versus (2) a context in which this history of cooperation is lacking.

One important difference that we expect to observe between the two different trajectories is the relative importance of formal versus informal joint actions. Cooperation driven by national initiative will typically occur through formal joint actions, such as administrative regulations, incentive policies, and supra-local organizations, which are usually established by supra-local governments that act as a lead organization [46]. These institutions raise formal requirements that all actors involved in the cooperation should adhere to in the performance of their activities [47]. However, when the involved actors have a history of cooperation it is likely that informal systems of rules, monitoring and sanctioning are already in place [48-51]. Rather than having a lead organization that sets the terms for cooperation, these informal systems depend more heavily on horizontal, face-to-face meetings between the cooperating partners [52], and a more tacit sense of partner accountability that is based on accumulated trust and mutual understanding [53-55]. Informal systems for cooperation may also remain dominant when formal systems are introduced alongside them, because they often work more rapidly and efficiently, being able to tap from an existing reservoir of trust and mutual understanding between the cooperating partners [38]. In a context where no history of cooperation exists, we expect formal mechanisms to dominate instead. We summarize these points in the following propositions:

Proposition 1. In trajectories of cooperation with no history of cooperation, formal joint actions will be more important in determining city-level environmental governance activities than informal joint actions. 
Proposition 2. In trajectories of cooperation with a history of spontaneous cooperation, informal joint actions will be more important in determining city-level environmental governance activities than formal joint actions.

A second important difference that we expect to observe concerns the "actor structure" of cooperation [55]. As mentioned in the beginning of Section 2, an actor refers to any governmental organization, NGO, and top elected official that has direct influential power on environmental governance. Actor structure, then, refers to a pattern of relationships between the set of actors involved in a cooperation, as well as the importance and role of these actors across longer sequences of events. In the previous paragraph, we already raised the suggestion that cooperation driven by a national initiative typically involves interventions by some supra-local agent. This idea is akin to what Feiock [31] refers to as constructed networks, which "encompass mechanisms designed or coordinated by third parties such as higher-level government to structure multilateral relationships across related policy areas", where "[a] higher level authority provides funds and incentives for actors to participate in [cooperative] arrangements" (p. 402). By contrast, in spontaneous cooperation we expect the structure of cooperation to resemble what Feiock [31] refers to as informal networks, which "provide the greatest local autonomy and can foster norms of trust", and are characterized by "[r]epeated face-to-face interaction [ . . ] ] in order for norms of reciprocity to develop and cooperative agreements to form" (p. 402). In the constructed networks, we expect there is a stronger role for lead organizations that play a relatively central role in what decisions get made [55], whereas in informal networks, cooperation is more distributed and decentralized, without a very clear role for a separate governance entity [55]. Given the background of the Chinese state government's push for inter-city cooperation on environmental governance, some role for a separate, supra-local entity that "mandates" cooperation likely exists in both our cases. However, we propose that the degree of centralized coordination in the latter situation should be much lower, as actors often coordinate their activities without going through a lead organization. These points are summarized in the following propositions:

Proposition 3. In trajectories of cooperation with no history of cooperation, joint action is coordinated primarily by supra-local lead organizations, in a centralized way.

Proposition 4. In trajectories of cooperation with a history of spontaneous cooperation, joint action is coordinated primarily among city-level leaders, in a decentralized way.

We now get to the core point of our central research question, which is the relative effectiveness of the two trajectories of environmental governance that we distinguish. At its very basis, effectiveness is about the extent to which predetermined goals have been realized. With cooperation on environmental governance, the Chinese central government hopes to increase the cities' awareness of interdependence, reconcile conflictual situations, and improve coordination among cities on task allocation to those who may bear them in the best way. As a measure of these effects, we make use of the concept of goal intertwinement, as discussed by Koppenjan [14]. Koppenjan [14] suggests goal intertwinement as a criterion of evaluation of the success of cooperation: "to what extent do outcomes intertwine actor's diverging objectives and/or reduce or compensate the costs and negative side-effects?" (p. 701). Thus, a positive outcome situation would be one in which the cooperating actors were able to achieve their goals in a synergetic way. Thus, a positive outcome situation is one in which (1) the cooperating actors are able to develop creative, synergetic solutions that meet the aims of the various cooperating partners, and (2) the costs and benefits of those solutions are shared equally between the cooperating partners. From this perspective, a negative outcome situation is one in which the chosen solution meets the aims of only one or a few of the cooperating actors, and where the costs and benefits of the chosen solution are concentrated at particular (groups of) actors. These are the main criteria that we will use in our own assessment of the effectiveness of cooperation in our two cases.

Arguments can be made in favor of both types of trajectories. As we summarized in Proposition 1, we expect that in trajectories without prior spontaneous cooperation, formal forms of cooperation play a 
more important role than informal forms of cooperation. The advantage of formal forms of cooperation is that they define rules, roles, responsibility, and decision-making authority more explicitly [13], and therefore define more clearly what is expected from the involved actors. In Proposition 3 we raised the expectation that cooperation in the absence of prior spontaneous cooperative experience entails a cooperative structure with a stronger role for a supra-local lead organization. Provan and Kenis [55] suggest that networks that have a lead organization are typically more efficient than those where coordination is distributed. Moreover, lead organizations can mediate between actors that were previously unaware of each other, help reconcile conflicting goals, and are in a good position to mobilize other actors for cooperation.

In Proposition 2 we summarized our expectation that informal means of cooperation are more important in trajectories of cooperation on environmental governance where there is a history of spontaneous cooperation. Informal mechanisms of cooperation typically enable actors to act more rapidly than formal mechanisms [38], which may make it easier for the actors to coordinate their actions. In addition, there is also a greater chance that the cooperating partners have already developed common definitions of problems and solutions when cooperation already took place spontaneously, which means that it is easier for them to agree on what actions to take. In Proposition 4 we summarized our expectation that, in trajectories of cooperation on environmental governance where a history of spontaneous cooperation exists, there is a stronger role for decentralized coordination. Provan and Kenis [55] suggest that, although they are typically less efficient than centralized structures, distributed structures do offer much more flexibility, while the rigidness of centralized structures may have an alienating effect on the involved partners. The decentralized structures may require less effort to ensure the buy-in of those involved, which is an essential part of any form of cooperation.

To summarize our discussion, we form two additional propositions. In this case, our propositions are contrasting, and we build on the evidence from our case studies to decide which one is closer to empirical observations.

Proposition 5. Trajectories of cooperation with no history of cooperation are more effective in achieving goal intertwinement.

Proposition 6. Trajectories of cooperation with a history of spontaneous cooperation are more effective in achieving goal intertwinement.

\section{Methods, Case Areas, and Data}

\subsection{Event Sequence Analysis}

In this chapter, we summarize our research design, which builds heavily on an approach called Event Sequence Analysis (ESA), which is a set of methods and analytical tools that use longitudinal event data to describe and analyze how entities emerge, develop, and possibly dissolve over time. ESA is inspired by approaches developed in sociology [56,57], and organizational innovation studies [58,59], and has been applied before in studies of collaboration on industrial symbiosis [60], in studies of the durability of Chinese circular economy policies [61], and in a study of the evolution of environmental policy in the Dutch Chemical Sector [62]. In the application of ESA, the units of analysis are events and the relationships between these events. In the current study, the events of concern are the various autonomous and joint actions described in the conceptual section (see Table 1). The relationships between the events capture how the events created the conditions under which further events occurred.

In the next sub-section, we introduce the two cases that we considered in this study. This is followed by an explanation of our data collection and data coding procedures. In the last sub-section of this chapter, we describe the various tools that we used for analysis, and we describe how our use of these tools relates to our propositions. 


\subsection{The Case Areas}

In this article, we analyze and compare cooperation on environmental governance in two large national urban agglomerations, the Beijing-Tianjin-Hebei (BTH) agglomeration and the Yangtze River Delta (YRD) agglomeration. BTH, which lies in the heart of the Chinese Bohai Sea region in Northern China, covers Beijing, Tianjin and another 11 municipalities in Hebei province. The area of BTH is about $218,000 \mathrm{~km}^{2}$ where some 110 million people reside. Actor interactions of BTH take place among the Beijing municipality, Tianjin municipality, and Hebei provincial government, while the 11 cities in Hebei province are not directly involved in interactions at the agglomeration level. Economically speaking, BTH is historically home primarily to heavy industries and manufacturing, with a shared GDP of 6.88 trillion RMB in 2016. In recent years, BTH has been facing serious air pollution problems. Furthermore, there are increasing concerns about soil erosion, water security and pollution, loss of biodiversity, and other serious environmental problems [63-66].

YRD, located in south eastern coastal China, is one of the most developed, densely populated, and economically vibrant regions in China [67]. It is strong in finance and export processing as well as heavy industries. It covers an area of $354,400 \mathrm{~km}^{2}$ and is home to over 227 million people as of 2016. The major actors in YRD's environmental governance are the Shanghai municipality and three provincial governments of Jiangsu, Zhejiang, and Anhui, while cities within the three provinces usually do not directly engage in coordination and negotiation at the agglomeration level. Benefiting from a high level of economic development and rapid urbanization, YRD contributed $19.78 \%$ of the nation's GDP in 2016, reaching 14.71 trillion RMB. The promotion of the region's economic development and ongoing urbanization within the recent national development strategy can be expected to usher in a new development peak in the YRD, with accompanying resource and environmental issues which may be prominent at the agglomeration scale [68].

\subsection{Data Collection and Coding}

The conceptual framework outlined in Section 2 provides guidelines in collecting longitudinal data on relevant events. The time span of the events in the two agglomerations is the period from 1992 (the starting point for the case study because that is when we already observe cooperation on various issues in Shanghai) to 2016 (the most recent year for which we recorded relevant activities). The events are recorded in Event Sequence Datasets, following examples of Poole et al. [59] and Spekkink [60]: Each event has a time stamp, a brief qualitative description of the action or interaction of concern, the actors involved, the type of action, and references to earlier events that conditioned its occurrence.

The data collection process for the two agglomerations started in May 2016 and was concluded in May 2017. Three researchers collected event data at the same time, and then synthesized the data to cross-check any missing events in individual collections. In the end, we collected 310 events as actions for environmental governance in BTH, and the figure for YRD is 295 events. The event dataset can be found in the Supplementary Materials of this article.

Our sources of data include web pages, media reports, academic papers, and various types of documents produced by the actors involved in environmental governance in BTH and YRD. The main webpages we searched include open information platforms of all involved governmental organizations (such as the municipal government, environmental protection bureau, the development and reform commission, etc.). In addition, we used baidu.com (it is a search engine affiliated to Baidu, Inc. that is one of the largest internet companies in the world; it is more likely to find information on events in China than with other search engines.) to find relevant webpages outside the governmental organizations. For media reports and academic papers, we used CNKI.net to search for data. The CNKI (China National Knowledge Infrastructure) contains information generated from scientific research, newspapers, conferences, and the statistics yearbook. For the government documents, we went to the electronic resource platforms of the city archives, which document past decisions made in relation to environmental governance. 
After data collection, we took four steps to prepare the data. First, we assigned a time stamp to each event, which indicates the date at which the event started (accurate to the day). This time stamp is used to determine the horizontal position of events in our event graphs, that is, their position on the visualized time line. Second, to create the event description, we largely depended on the content of the original sources of data. We read through all the collected materials, and we manually entered relevant information on the events into the dataset. The description of an event may be sourced from multiple observations (from different sources), and we retained and synthesized the information that reflects different aspects of an event, while removing the repeated information. Third, using qualitative coding procedures, we coded the data to qualify our events in two ways: (1) Based on information on the events provided in source materials we classified events into one of the event types as listed in our conceptual chapter (see Table 1); (2) We identified the actors involved in the events and associated these actors with the events by assigning codes. Fourth, we used two main criteria to establish the existence of relationships between events: (1) Since the events of concern refer to actions by governmental actors, we studied documents produced by these actors to identify the linkages between events. For example, in explaining the reason for taking certain actions, governmental actors occasionally refer to earlier events; (2) News and reports also provided indicators for linkages between events, by describing how "current events" are rooted in earlier developments. If either of these situations occurred for a given pair of events, we created a relationship between the two events.

\subsection{Data Analysis}

We adopt a combination of analytical tools to test our propositions. Table 2 offers an overview of our propositions, the approaches that we used to test these propositions, and the indicative patterns that we expect to observe in case the corresponding proposition holds.

Table 2. A summary of propositions, testing approaches, and indicative patterns.

\begin{tabular}{|c|c|c|c|}
\hline Propositions & Indicative Patterns & Analytical Tools & Descriptors \\
\hline Proposition 2. & $\begin{array}{l}\text { Where city level governance activities } \\
\text { follow joint actions, they tend to follow } \\
\text { more often from informal joint actions } \\
\text { than formal joint actions. }\end{array}$ & Event Graph & $\begin{array}{l}\text { Qualitative description of an event; } \\
\text { Directed edges between events. } \\
\text { Out-degree of a node: the number of later } \\
\text { events, to which an event is related (i.e., a } \\
\text { node). }\end{array}$ \\
\hline Proposition 3. & $\begin{array}{l}\text { Joint actions are brought about } \\
\text { primarily by supra-local actors. }\end{array}$ & \multirow{2}{*}{$\begin{array}{l}\text { Two-mode } \\
\text { actor-event } \\
\text { networks }\end{array}$} & \multirow{2}{*}{$\begin{array}{l}\text { Attribute of an actor; } \\
\text { Edges between actors and joint actions; } \\
\text { Betweenness centrality: a node with higher } \\
\text { betweenness centrality would have more } \\
\text { control over the network, because more } \\
\text { information will pass through that node. }\end{array}$} \\
\hline Proposition 4. & $\begin{array}{l}\text { Joint actions are brought about } \\
\text { primarily by local actors. }\end{array}$ & & \\
\hline Proposition 6. & $\begin{array}{l}\text { Cooperation in a historical context of } \\
\text { prior cooperation leads to } \\
\text { intertwinement of goals of involved } \\
\text { actors and reduced or compensated the } \\
\text { costs and negative side-effects. }\end{array}$ & $\begin{array}{l}\text { Qualitative } \\
\text { assessment }\end{array}$ & $\begin{array}{l}\text { Qualitative description of an event; } \\
\text { Directed edges between events. }\end{array}$ \\
\hline
\end{tabular}

One type of analytical tool that we use is an event graph, which is an a-cyclic, directed graph in which the nodes represent events, and the edges represent relationships between events. The horizontal layout of the nodes is based on the time of occurrence of their corresponding events. Nodes that represent events that happened relatively early are thus located in the left area of the event graph, and nodes that represent events that happened relatively late are located in the right area of the 
event graph. We used the vertical layout of the node to (roughly) indicate where the events occurred geographically. The events either occurred in one of the cities of our UAs, or they occurred at the supra-local (UA) level. In the event graphs that we use in this paper, the labels of the nodes are the unique identifiers we assigned to events. The colors of the nodes indicate what type of event the nodes represent. The event graphs serve to offer abstract visualizations of the processes under study, and contain all the information that we need to test our first two propositions. Specifically, in the event graph we measure (1) proportions of the two types of joint actions as proxies for the scale and dominance of these different types, and (2) the number of later autonomous actions, to which a joint action is related (i.e., the out-degrees of joint actions) as proxies for the joint actions' importance in bringing about autonomous events.

A second type of analytical tool that we use is a two-mode graph of actors and events. In this graph, the nodes represent either actors or events (distinguished by different colors), and the edges (i.e., the relationships between pairs of nodes) represent which actors were involved in which events. We created these graphs only for joint events, in order to study which actors played a role in these events. This allows us to assess the extent to which local and supra-local actors were responsible for bringing about cooperation. We use this tool to test propositions three and four.

To test our final two propositions, we use a qualitative assessment of the results that have been achieved so far in the two cases. Here, we rely on our all sources that we have gathered to get a picture of how well the actors have been able to create a level playing field, that is, to what extent the outcomes of cooperation have (1) intertwined the diverging objectives of the involved actors and (2) reduced or compensated the costs and negative side-effects. Given that it is hard to develop objective measures of these criteria, our focus here is on providing clear arguments for the assessment that we provide of them.

\section{Empirical Findings}

In this section we present our empirical observations. We start with a general description of our findings, which is built around our event graphs, discussing the case of BTH (Section 4.1) and YRD (Section 4.2) in sequence. Here, we focus on broader patterns that are relevant for testing our propositions. We conclude this part of our analysis with some basic quantitative measures that we use to determine the relative importance of FJA and IJA actions in our two cases. In Section 4.3 we offer an analysis of the participation of actors in the joint actions observed in our cases. We conclude with Section 4.4, in which we discuss the outcomes of cooperation, and how these can be understood based on our other empirical observations.

\subsection{The Event Graph of Environmental Governance Trajectory in BTH}

The event graph of environmental governance trajectory in BTH is shown in Figure 1. Before 2013, the member cities of BTH worked on environmental protection autonomously. They generally took autonomous actions that centered around the formulation of environmental legislation, regulations and programs from scratch. Environmental enforcement actions are sporadic, and have aroused only few further environmental protection actions [69].

Specifically, Beijing focused on air pollution prevention and control by developing Periodic Measures to Control Air Pollution (events B5, B9, B13-B15, B22), formulating the Beijing Clean Air Action Plan (events B25, B28, B29, B35, B36), and establishing the Total Pollutant Emission Reduction Plan (events B26, B31, B32). Like Beijing, Hebei's autonomous actions also lay in legislation of environmental protection. In addition to that, Hebei was the first to release Measures for Collection and Usage of Pollution Discharge (event H10), and these Measures evoked a series of enforcement actions on illegal pollution discharges by enterprises (events H11-H18). To further support enforcement of the Pollution Discharge Measures, Hebei issued the Plan of Ecological and Environmental Monitoring Pilot Project (event H19) in several of its municipal cities (events H23-H26, H28). In addition, the 
Hebei provincial government put forward the Energy Saving and Emission Reduction "Double Thirty" Project and released annual implementation plans for this project.

Tianjin is similar to its peers in the agglomeration. Its focus lay in building rule of law, while little attention was paid to legal enforcement. The major events were the establishment of the Tianjin Eco-City Construction Plan (event T13) and its affiliated Annual Environmental Protection Work Points (events T14-T17, T19).

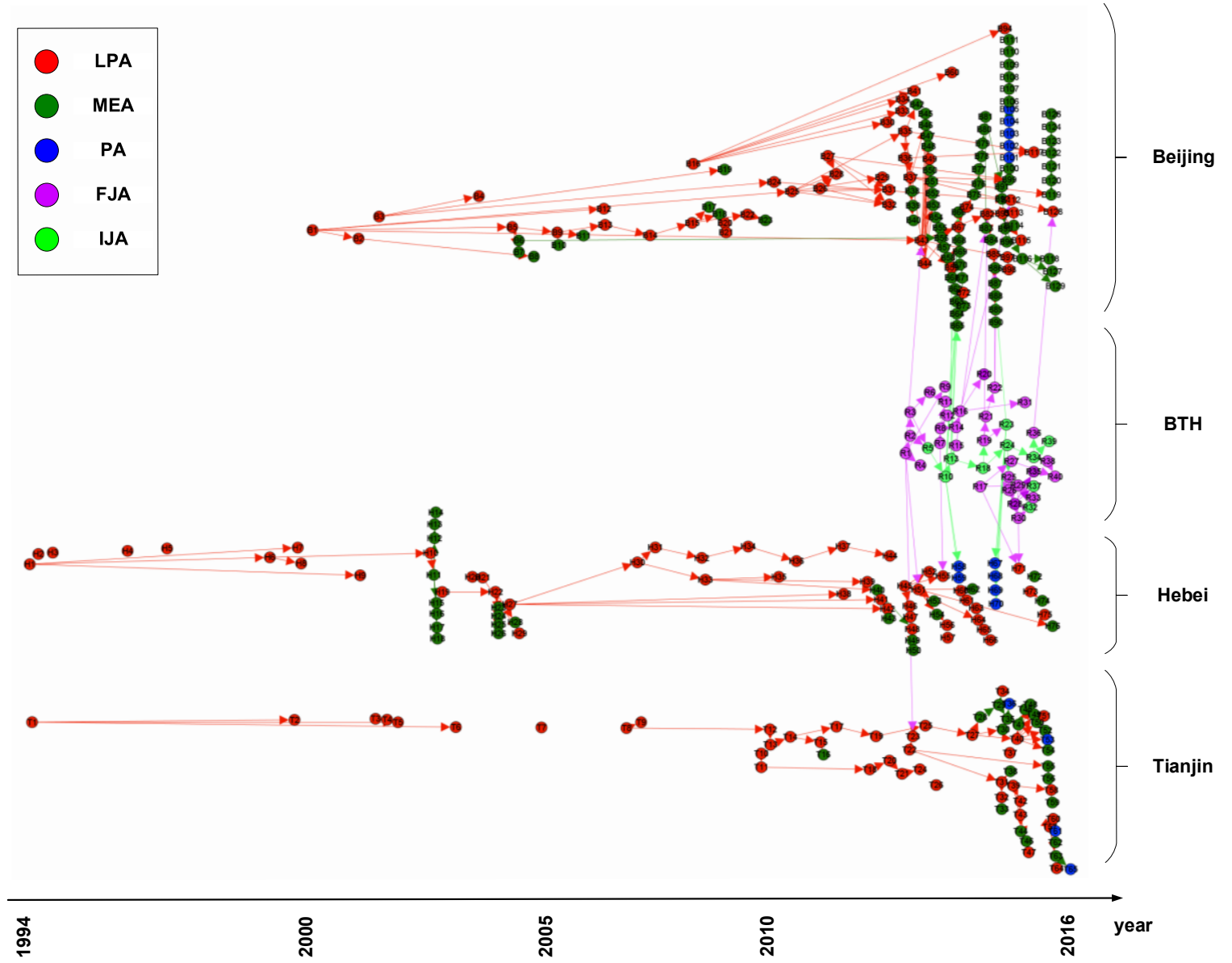

Figure 1. Event group of cooperation in environmental governance in Beijing-Tianjin-Hebei (BTH). Nodes represent events and edges represent relationships between events. The colors represent different types of events (see legend). The horizontal layout of the nodes is based on the time of occurrence of events, and the vertical layout is based on the location where the events happened.

The location is also emphasized by the boundaries drawn around groups of events.

In BTH the formal joint action started with the introduction of the Action Plan for BTH and the Surrounding Areas to Implement Air Pollution Control in September 2013 (R1), after the State Council established UAs [70]. In October 2013, the Coordination Office of Air Pollution Control in BTH and the Surrounding Areas (R2, R3) was established by the Ministry of Environmental Protection (MOEP), involving actors from environmental, meteorological, energy, traffic, industrial, and financial ministries, as well as mayors and governors from the agglomeration. Since then, periodic meetings were held among the delegates from the above-mentioned organizations to discuss the joint measures to control air pollution (events R5, R10, R13, R18, R24, R34, R39). Each meeting produced Annual Key Points or Strengthening Measures of Air Pollution Control in BTH, which were supposed to guide both LPA and MEA in the member cities. In addition, one noticeable joint action (R17) was the issuance of the Outline of Coordinated Development Plan in BTH by the CPC Politburo in early 
2015, which proposes that industrial upgrading and transfer (from Beijing and Tianjin to Hebei) and stricter and more intense environmental inspections are the most compelling and urgent tasks in BTH to achieve collective development goals of the agglomeration. In other words, the Plan stated that the nation requires Hebei to take over the industries of Beijing and Tianjin, while engaging in more intense environmental inspections and investments [71].

After the joint actions to control air pollution, the three major member cities issued several other inter-local agreements and plans. They expanded cooperation in water pollution control (R16, R20), the promotion of electronic vehicles (R15), and motor vehicle emission control (R21, R22). Building on these formal joint actions, the three city regions established an Office for Joint Environmental Inspection (R26, R28, R37) and decided to promote joint legislation for environment protection (R27). While these events were unfolding, the MOEP and the National Development and Reform Commission (NDRC) introduced several regional cooperation plans, including an Eco-Environmental Protection Plan (R29) and the Strengthening Measures for Air Pollution Control in BTH (R36). Intertwining with these national initiatives were the voluntary initiatives by the three city regions to establish an Information-Sharing Platform for Air Quality (R33) and a Standard for Volatile Organic Compounds (R38, R40).

The autonomous actions at the city level are much more intense after initial cooperation on air pollution control. In the Beijing case, the R1 joint event brought about the Regulations on Air Pollution Control in Beijing (B43) that evoked further environmental legislation (B49, B59, B67, B82, B93, B97, B98, B115) and more frequent enforcement actions (weekly and monthly environmental inspection events B45, B47, B48, B50, B51, B53, B68, B84). In addition, the periodic meetings at the agglomeration level also safeguarded the regular and constant inspection activities (events B63-B66, B86-B88). Different from Beijing, the impact of cooperation on Hebei's autonomous actions is limited to legislative improvements. Event R1 brought about the Opinions on Tackling Most Difficult Environmental Problems in Hebei (H51), and the 2014 Key Points of Air Pollution Control in BTH Agglomeration (R7) brought about the 2014 Plan for Air Pollution Control in Hebei (H55). In addition, we see that the 2nd and 3rd periodic regional meetings brought about political actions (Hebei leaders gave several speeches and conducted surveys in environmental protection, events $\mathrm{H} 58, \mathrm{H} 59, \mathrm{H} 67-\mathrm{H} 70$ ), but these events did not lead to further enforcement activities. The cooperation has had little impact on Tianjin's autonomous actions. Event R1 led to the establishment of the Emergency Plan for Heavy Pollution Weather in Tianjin (T23), but no further events were aroused by cooperation at the agglomeration level.

\subsection{The Event Graph of Environmental Governance Trajectory in $Y R D$}

Different from the BTH case, cooperative initiatives on environmental governance in the YRD agglomeration took place from the early stages of our observation period (Figure 2) [9]. In 1992, mayors of fifteen cities (Shanghai, Wuxi, Ningbo, Zhoushan, Suzhou, Yangzhou, Hangzhou, Shaoxing, Nanjing, Nantong, Taizhou, Changzhou, Huzhou, Jiaxing, and Zhenjiang) in the YRD area set up the joint meeting system (Y1) in order to promote economic cooperation and environmental sustainability. In 1997, this joint meeting system was upgraded to the YRD Urban Economic Coordination Meeting (UECM). The UECM, as well as the following mentioned meetings and forums, do not appear on any organizational chart; they are convened irregularly, and developed on the basis of need. Participation in the meetings is voluntary, and they can, but not necessarily produce formal agreements. Until 2016, the mayors jointly organized 16 meetings (Y2-Y7, Y9, Y10, Y14, Y18, Y21, Y24, Y27, Y31, Y37, Y43), and some of the meetings produced key strategies and plans to implement economic cooperation projects and environmental protection approaches. These events, which we categorized as IJA, had profound impacts on the joint and autonomous actions of member cities.

The mayors engaged in repeated interactions on various topics related to urban economic coordination. In our event graph, this is visible as four types of events that spring from the 6th UECM, and that unfolded more or less in parallel to each other. The first one is the YRD Major Leader Forum (MLF), which was held seven times irregularly throughout 2005-2016 (events Y8, Y11, Y23, 
Y26, Y29, Y36, Y49). This forum mainly dealt with ecological and environmental protection issues in the YRD agglomeration, and generated general cooperative strategies and guidance. The second type of events is the YRD Joint Meeting on Cooperation and Development (JMCD) (Y16, Y20, Y22, Y28, Y33, Y41, Y47, during 2009-2016). The JMCD focused on establishing specific cooperative projects across jurisdictional boundaries and in different sectors (e.g., transport, energy, environmental, health care, etc.). The third type comprises the Joint Meeting on Environmental Protection Cooperation (JMEPC) (Y17 in 2009, Y25 in 2012). The JMEPC was later replaced by the fourth type of events called Working Meeting on Air Pollution Prevention and Control (WMAPPC) (Y30, Y32, Y34, Y38, Y40, Y42, Y44, Y46, during 2014-2016) [67].

The UECM alone (before 2006) has already had an impact on autonomous actions in Shanghai, Jiangsu, and Zhejiang. The 1st, 2nd, and 3rd meetings of UECM (Y2-Y4) drove the event Z1, in which Zhejiang Provincial Party Secretary led a delegation to start a two-day study tour of Shanghai. The aim of the tour was to propose the establishment of the meeting system among major leaders in the YRD area (the driver of Y8). Thus, the political action of Zhejiang had a positive influence on cooperation in YRD.

Within Zhejiang, the tour led to a government document titled "Opinions on the active convergence of Shanghai and active participation in the YRD cooperation and exchange" that became the foundation for future active involvement of Zhejiang in YRD cooperation. The 4th meeting of UECM (Y5) also has significant influence on autonomous actions for environmental governance, because this meeting first recognized the importance of cooperation on environmental governance in YRD. It brought about several events of legislation building in Shanghai (S1-S3), Jiangsu (J2, J3) and Zhejiang (Z3, Z4). Anhui officially joined the YRD agglomeration in 2008, so Anhui was not clearly involved in or affected by events that occurred prior to 2008. Since 2005, the UECM, MLF, JMCD, and WMAPPC have been working in parallel, and aroused many autonomous actions in individual member cities. As we can see, the meetings at the agglomeration level evoked LPA, MEA, and PA in Shanghai, Jiangsu, and Zhejiang. Furthermore, the PA events in the three city regions generated far-reaching effects on enforcement improvements. Many more environmental inspection events were conducted after certain political actions took place.

Table 3 summarizes some of the quantitative descriptors that we derived from our event graphs, including the relative amounts of FJA and IJA, as well as the number of autonomous actions following from them. The table shows that in the BTH case FJA actions are dominant, while in the YRD case IJA actions are dominant. This is in line with our expectations that, when there is a history of spontaneous cooperation, informal joint actions remain dominant, while without a history of cooperation formal joint actions tend to dominate. Our Proposition 1 suggests that FJA actions should also be more influential in bringing about autonomous actions at the city level. However, the absolute numbers of autonomous actions following from FJA and IJA actions in the case of BTH are equal. If we consider that IJA actions occurred much less frequently, we could draw the conclusion that IJA actions were in fact more influential in bringing about subsequent autonomous actions in this case. Thus, Proposition 1 is not supported by our findings, but Proposition 2 is supported, as we find that IJA are followed by autonomous actions more often than FJA actions, although our findings on the BTH case specifically are less conclusive on this matter. 


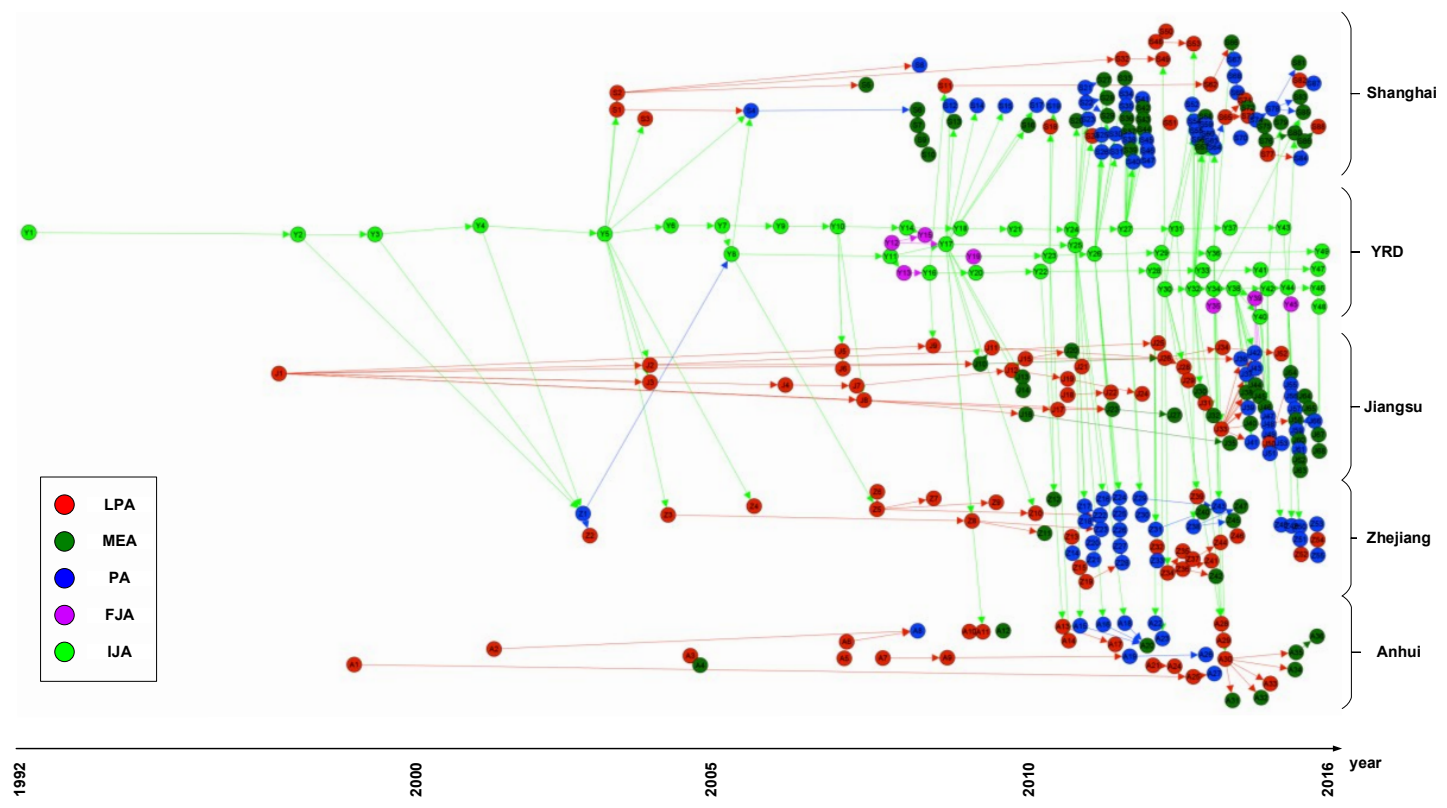

Figure 2. Event graph of cooperation on environmental governance in Yangtze River Delta (YRD). Nodes represent events and edges represent relationships between events. The colors represent different types of events (see legend). The horizontal layout of the nodes is based on the time of occurrence of events, and the vertical layout is based on the location where the events happened. The location is also emphasized by the boundaries drawn around groups of events.

Table 3. Proportions of FJA and IJA in Beijing-Tianjin-Hebei (BTH) and Yangtze River Delta (YRD). * In the measurement of outdegree of joint actions, we focused exclusively on autonomous actions that followed from the joint actions.

\begin{tabular}{|c|c|c|c|c|c|}
\hline UA & $\begin{array}{l}\text { Type of Joint Action } \\
\text { (Absolute Amount) }\end{array}$ & $\%$ & $\begin{array}{c}\text { Total Number of } \\
\text { Following } \\
\text { Autonomous Actions }\end{array}$ & $\begin{array}{l}\text { Top } 5 \text { Outdegree } \\
\text { Joint Actions* }\end{array}$ & $\begin{array}{l}\text { Quantity of Following } \\
\text { Autonomous Actions }\end{array}$ \\
\hline \multirow{13}{*}{ BTH } & \multirow{10}{*}{ FJA (30) } & \multirow{10}{*}{$75.0 \%$} & \multirow{10}{*}{13} & R1 & 3 \\
\hline & & & & R3 & 2 \\
\hline & & & & R7 & 1 \\
\hline & & & & R15 & 1 \\
\hline & & & & R16 & 1 \\
\hline & & & & R17 & 1 \\
\hline & & & & R19 & 1 \\
\hline & & & & R22 & 1 \\
\hline & & & & R29 & 1 \\
\hline & & & & R36 & 1 \\
\hline & \multirow{3}{*}{ IJA (10) } & \multirow{3}{*}{$25.0 \%$} & \multirow{3}{*}{13} & R10 & 5 \\
\hline & & & & R23 & 5 \\
\hline & & & & R13 & 3 \\
\hline \multirow{6}{*}{ YRD } & FJA (7) & $14.3 \%$ & 4 & Y39 & 4 \\
\hline & \multirow{5}{*}{ IJA (42) } & \multirow{5}{*}{$85.7 \%$} & \multirow{5}{*}{122} & Y27 & 14 \\
\hline & & & & Y17 & 12 \\
\hline & & & & Y26 & 12 \\
\hline & & & & Y25 & 11 \\
\hline & & & & Y32 & 11 \\
\hline
\end{tabular}

\subsection{The Participation of Actors in Bringing about Joint Actions}

Figures 3 and 4 show the participation of actors in joint actions in BTH and YRD respectively. Full names of actors are shown in the Supplementary Materials. The two cases show substantial differences in actor roles in initiating the joint actions. First, in the BTH case, 20 out of 34 actors come from national government organizations (including eight large state-owned enterprises directly under administration of the State Council), who mobilized significant resources and gave critical 
momentum to initiating joint actions. For instance, the first joint action, the Action Plan for BTH and the Surrounding Areas to Implement Air Pollution Control, was jointly put forward by six ministries at the national level. The Air Pollution Control Leading Group was also established by the MOEP, who pulled in actors not only from industrial sectors but also from local governments. To strengthen the implementation of the Action Plan, the MOEP organized seven Regional Air Pollution Joint Defense Joint Control Symposiums and formulated several working plans, including for air pollution control, water management, and ecological protection. Based on these first joint initiatives (21/40 actions), local actors in BTH gradually started to formulate inter-local agreements, joint environmental standards, and information-sharing mechanisms (19/40 actions). Thus, in the BTH case supra-local authorities, and the MOEP in particular, were dominant in the early stages of cooperation, while local actors became more dominant in the stages following them. This provides partial support for our Proposition 3, which predicts a dominant role for supra-local actors, but does not predict a gradual shift towards increased dominance of local actors.

The YRD case shows a different story. 10 out of 49 actors are national government organizations that did not participate in the initial joint actions but became involved in YRD's environmental governance in a much later phase, primarily helping in drawing up the air pollution control action plan (10/49 actions). As we showed in the previous section, the main initiators for 39/49 joint actions are local actors in the YRD region, who met in cooperation and coordination forums and unions to tackle regional economic and environmental issues. Table 4 also shows that in YRD all the central actors are local actors who are also affiliated to most of the joint actions. These findings are in line with what our Proposition 4 predicts about the dominance of city-level actors in the coordination of the cooperation when there is a history of cooperation.

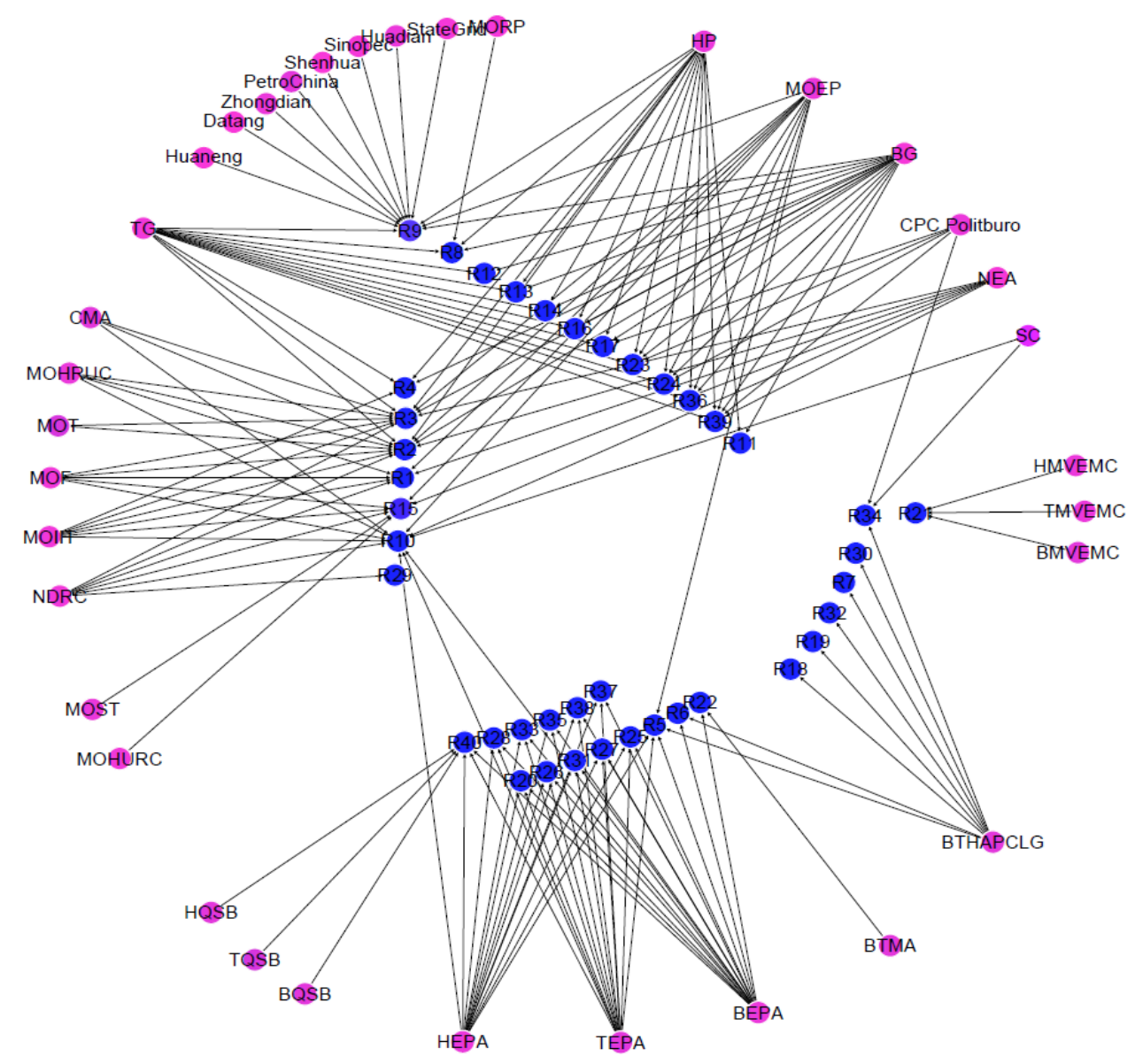

Figure 3. Two-mode network showing the participation of actors in bringing about joint actions in BTH. 


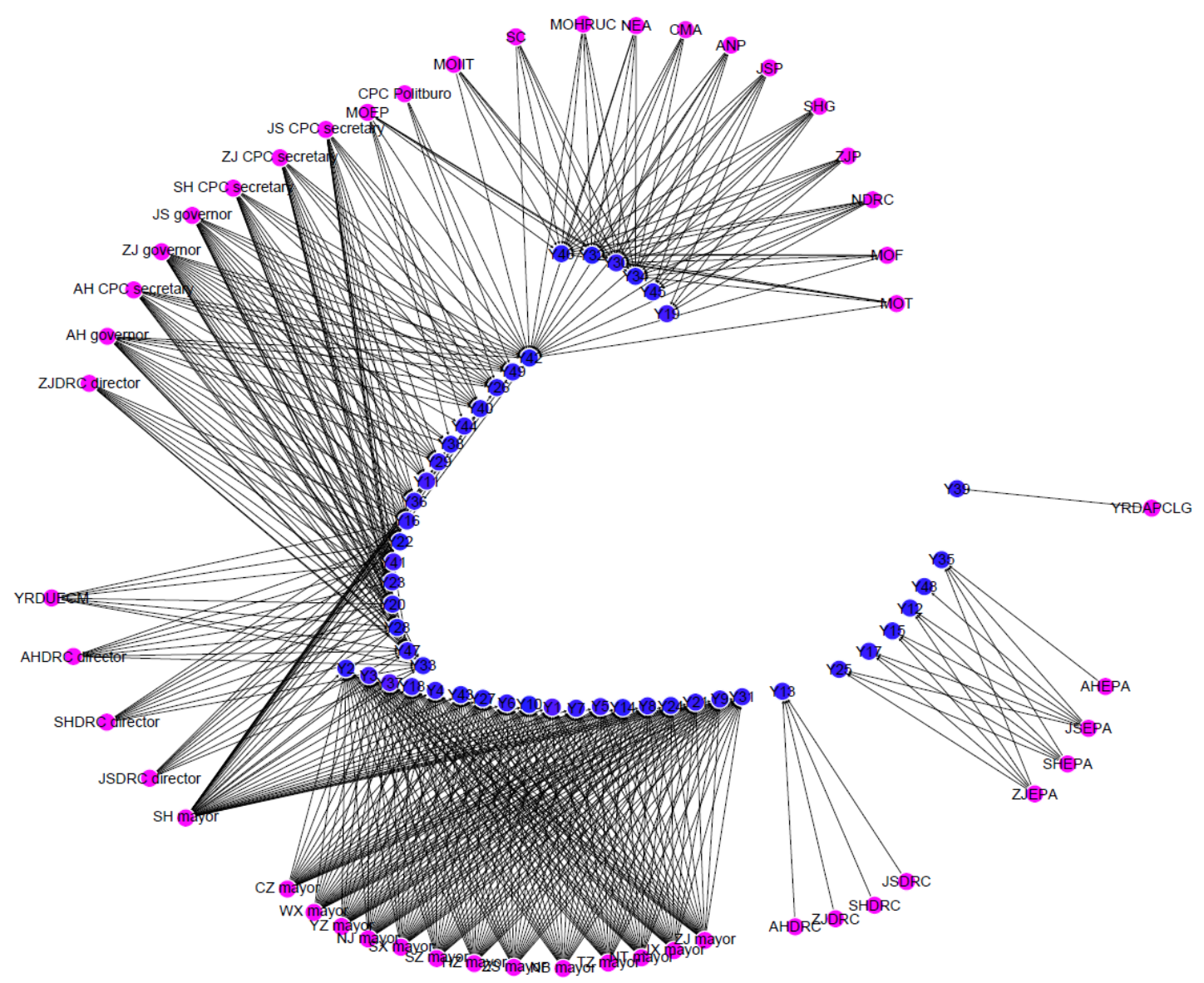

Figure 4. Two-mode network showing the participation of actors in bringing about joint actions in YRD.

Table 4. The top 5 most central actors in BTH and YRD to bring about joint actions.

\begin{tabular}{cccc}
\hline UA & Actor & Betweenness Centrality & No. Joint Actions in Which Actor Participates \\
\hline \multirow{4}{*}{ BTH } & MOEP & 21.583 & 12 \\
& BEPA & 6.477 & 15 \\
& TEPA & 6.477 & 13 \\
& HEPA & 6.477 & 13 \\
& BG & 5.009 & 15 \\
& TG & 5.009 & 14 \\
& HP & 5.009 & 14 \\
& NDRC & 1.511 & 6 \\
& MOIIT & 1.511 & 6 \\
MOF & 1.511 & 5 \\
\hline \multirow{4}{*}{ YRD } & 31.763 & 34 \\
& SH mayor & 0.811 & 14 \\
& JS CPC secretary & 0.811 & 14 \\
ZJ CPC secretary & 0.811 & 14 \\
& SH CPC secretary & 0.811 & 15 \\
AH CPC secretary & 0.811 & 16 \\
JS governor & 0.595 & 17 \\
ZJ governor & 0.595 & 8 \\
& AH governor & 0.017 & 8 \\
\hline
\end{tabular}

4.4. The Outcomes of Cooperation on Environmental Governance in BTH and YRD

With regard to the outcomes of the cooperation on environmental governance we see some important differences between the cases of BTH and YRD. 
In BTH, especially in the early stages, the terms for cooperation were set primarily by supra-local actors, including the CPC Politburo, which was perhaps the most powerful decision-maker in China with its ability to overrule provincial and municipal leaders in the appointment of personnel. Their Outline of Coordinated Development Plan in BTH, alongside other joint initiatives brought forward by government authorities (see Section 4.2), created a cooperative structure with an unequal playing field for Beijing, Tianjin, and Hebei. The plan sets up a "fifty-fifty" structure for tax revenue allocation. In this plan, Beijing and Tianjin retained the headquarters (management organs) of industrial enterprises, and transferred their polluting production sites to Hebei. By doing so, Beijing and Tianjin retained $50 \%$ industrial tax revenues and concurrently shifted $50 \%$ of their tax incomes and $100 \%$ of their environmental burdens to Hebei. In reality, Hebei used up their tax revenues to invest in the construction and maintenance of industrial zones. Until 2016, Hebei developed 213 industrial development zones, and 886 industrial transfer projects (756 from Beijing). Steel and cement enterprises with high pollution records all moved from Beijing and Tianjin to Hebei. This large scale industrial transfer, within a relatively short period of time, generated enormous environmental challenges for Hebei, while the city lacked the capacity to carry out inspections or alleviate heavy pollution on such a large scale.

As we discussed in Section 4.1, one effect of cooperation on environmental governance in the BTH case has been new environmental legislation and more frequent enforcement activities in the city of Beijing. However, in the cities of Hebei and Tianjin the joint actions had little impact on city-level activities. In addition, the three regions in BTH agglomeration have few direct interactions at present, and to a larger extent rely on centralized arrangements. Especially for Hebei, the efforts and commitment to cooperation on environmental governance are rather weak. Beijing and Tianjin are also reluctant to initiate direct dialogues with Hebei, and they often rely on central interventions to enforce action by Hebei.

In summary, in the case of BTH there is no level playing field for the actors involved in environmental legislation at the UA level, and the interests of the involved actors are not served equally. Moreover, the costs and negative side-effects of the approach that has been chosen are largely concentrated with one actor, without clear compensation. Thus, we found no support for Proposition 5.

In the YRD agglomeration, before the national initiative for cooperation on environmental governance started in 2013, the cities had already convened 12 Economic Coordination Meetings, four Major Leader Forums, three Joint Conferences on Cooperation and Development, and two Special Sessions on Environmental Protection Cooperation (see Section 4.2). The emerging consensus of the member cities was to keep the existing industrial layout, jointly raise the environmental standards to the same level, establish regular joint environmental inspections, and to let enterprises freely choose their locations of establishment. In 2004, Special Funds for Economic Coordination in YRD were established, composed from investments from member cities. These funds were used to cover the administrative costs of cooperation on environmental governance. In 2008, a Cooperation Agreement on Environmental Protection in YRD was signed among the member cities, which formally set direction, authority, and rules of cooperation. In 2010, Funds for Joint Promotion of Cooperation and Development in YRD were established, for the purpose of supporting technical and managerial innovation projects facilitating cooperation in YRD. As we discussed in Section 4.1, the spontaneous cooperation between the cities has brought about new legislative and enforcement actions in all involved cities.

The cooperative structure that was already in place actually left little room for the national initiative, reflected by the persistent dominance of informal mechanisms of cooperation. The role of central governments therefore became to facilitate the existing cooperative process. For instance, in 2010, the National Development and Reform Commission (NRDC) issued the Regional Development Plan for YRD, which explicitly states that: "YRD has a good basis for cooperation on environmental governance; cities in YRD should carry on the good tradition and continue implementing the established joint agreements and plans." In 2016, the NDRC issued the Urban Agglomeration 
Development Plan for YRD, which again clearly states that: "there is no industrial transfer in YRD, only industrial upgrading through cleaner energy adoption and more pollution treatment devices; cities in YRD need to deeply enhance their joint-action mechanism."

In summary, in the case of YRD the playing ground for the involved actors is more even. Through their early cooperation, the member cities reached consensus about the common goals in environmental governance and the approach to be taken to reach these goals. Moreover, the costs involved with the cooperation are shared through jointly established funds. Comparing the two cases on outcomes, the cities in the YRD agglomeration thus have been more successful in achieving goal intertwinement. If we look beyond the cooperation itself, we see indications that cooperation in YRD has been effective also in a more "material" sense. Comparing the amount of industrial sulfur dioxide emission in BTH and YRD from 2000 to 2015 (see Figure 5a,b), we see a decline in sulfur dioxide emissions in BTH, Beijing, and Tianjin since 2011, but a sharp increase in Hebei since 2011, which is an indicator that some environmental problems have simply been displaced. In YRD, a collective decline in the amount of industrial sulfur dioxide emissions is observed since 2011. Based on the above mentioned evidence, we conclude that Proposition 5 does not hold, while Proposition 6 is supported by our findings. Thus, Proposition 6 is supported by our findings.

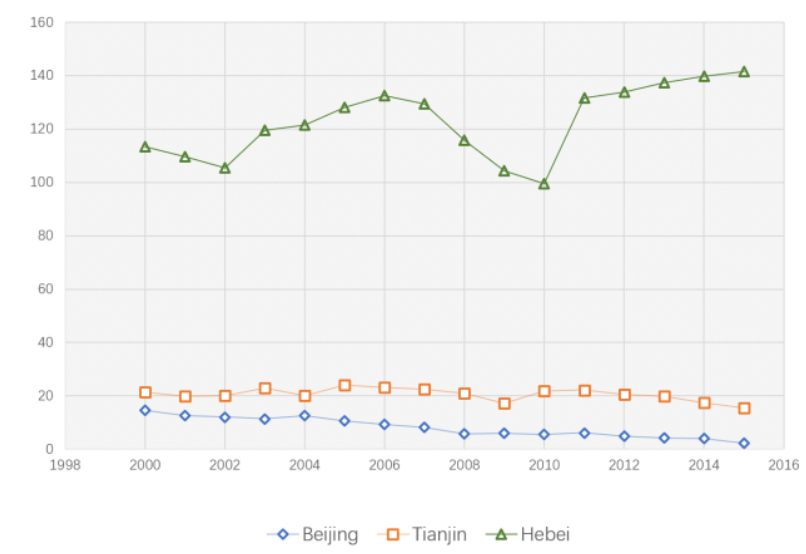

(a)

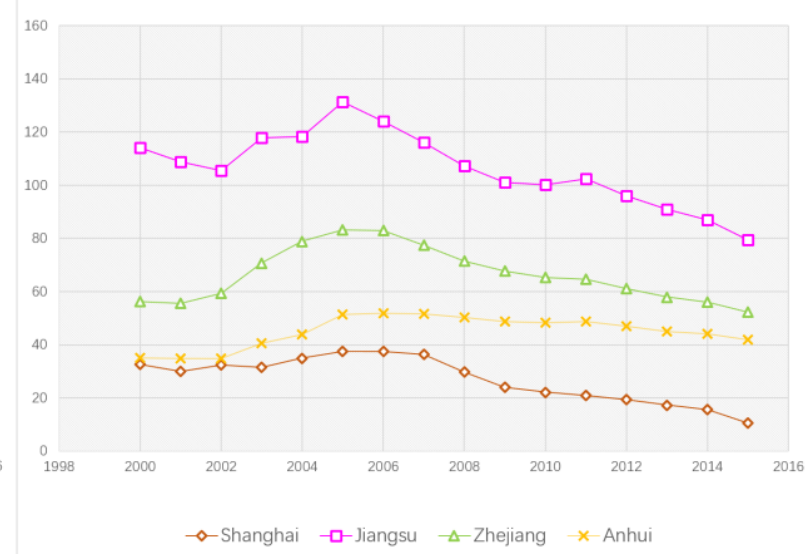

(b)

Figure 5. Industrial sulfur dioxide emissions (10 thousand ton) in BTH and YRD, 2000-2015. (a) (on the left) shows the amount of industrial sulfur dioxide emission in BTH from 2000 to 2015; (b) (on the right) shows the amount of industrial sulfur dioxide emission in YRD from 2000 to 2015.

\section{Conclusions}

The goal of this study was to explore the effectiveness of cooperation on environmental governance in two contrasting contexts: (1) a context in which there is a history of spontaneous cooperation, and (2) a context where there is no history of cooperation. Conducting the ESA and associated network analysis proved fruitful for gaining an understanding of how environmental governance trajectories that unfolded in these different contexts link to the effectiveness of cooperation on environmental governance. In general, our main finding is that trajectories of environmental governance that have a history of prior cooperation are more effective in achieving goal intertwinement than trajectories in which no such history exists. For this study, two dimensions stood out to distinguish the trajectories of environmental governance in BTH (no history of cooperation) and in YRD (with a history of spontaneous cooperation). One is the importance of formal versus informal forms of joint actions in arousing autonomous actions by the cooperating partners, and another is the role of supra-local versus local actors in coordinating joint actions. We found that informal joint actions, along with decentralized coordination by local actors, are associated with more effective cooperation. Interestingly, in the BTH case, we also found that informal joint actions are relatively more potent in bringing about 
autonomous actions, even though the occurrence of this type of action was relatively rare in this case. This again implies that informal forms of cooperation have stronger power in bringing about city-level environmental governance actions than formal ones.

While having the conditions of the presence of informal joint actions and the existence of decentralized local actor coordination in place, are conducive to far more effective cooperation, they are certainly not sufficient conditions. Evidence from our qualitative assessment in Section 4.4 (sourced from detailed policy contents in the event data) shows that the presence or absence of other conditions may become enablers or disablers for effective cooperation. In BTH, the higher-placed authority designed an uneven playing field for the member cities in the UA, which at least partially accounts for the undesirable results of cooperation in BTH. In the absence of prior cooperation (like BTH), there is an opportunity (e.g., for a higher-placed authority) to create a cooperative structure among the partners from scratch, but then particular attention should be paid to the creation of an equal playing field, with balanced costs and benefits for each partner. The incentive to participate, and be fully engaged and committed to cooperation will be stronger if the cooperating cities are treated equally and their costs can be sufficiently compensated.

In contrast, when there is a history of spontaneous cooperation, higher-placed authorities can still play an important role in the facilitation of cooperation on environmental governance. For example, in the YRD case the central government affirmed the ongoing cooperation and encouraged deeper cooperation in the future. Facilitation by a higher-placed authority external to the original group of cooperating partners, is conducive to effective cooperation because it offers the partners additional impulses to interact and come to a new understanding of their relationship, thereby increasing their sense of interdependence. The recognition of ongoing cooperation by a higher-level authority also provides that cooperation with stronger legitimacy. As we can see from the event graph of the YRD case, local actors' interactions became more intensive after the national initiative, suggesting that this further legitimization gave the process additional momentum.

In this article, we focused on two different cases of cooperation on environmental governance in China. Further research is required to assess the extent to which the conceptual arguments and empirical findings presented in the paper are generalizable to other urban agglomerations in China. An additional limitation of this article is that we restricted our focus to the influence of the absence or presence of prior cooperative experience on the effectiveness of cooperation. However, there may be other influential factors, such as incompatible or conflicting bureaucratic cultures, differences in the degree of environmental pollution in cooperating cities, and power imbalances between cities. For example, Beijing and Shanghai have relatively strong power positions in their respective UAs, and therefore have a stronger voice in deciding what pathways are taken in cooperation on environmental governance. In the BTH region, this may have compounded the relatively skewed distribution of costs and benefits that we observe there. However, we also observe that the city of Shanghai uses its relatively powerful position in a very different way, and we believe that prior cooperation with other cities in UA was an overriding factor here. That being said, we suggest that additional research is required as to how the presence or absence of a history of prior cooperation interacts with other historical conditions in shaping the effectiveness of cooperation in the present. For example, the presence/absence of prior cooperation could be simply taken as one historical condition among others, the importance of which is then to be examined through Qualitative Comparative Analysis [72]. In such an approach, the dynamics that show how these conditions lead to outcomes are necessarily lost, but our findings can be used as a background to such a study where it regards prior cooperation.

Supplementary Materials: The following are available online at http:/ /www.mdpi.com/2071-1050/10/6/1950/ s1, Appendix 1: Environmental governance actions in Beijing-Tianjin-Hebei urban agglomeration, Appendix 2: Environmental governance actions in Yangtze River Delta urban agglomeration, Appendix 3: Actor list.

Author Contributions: R.M. and W.S. contributed equally to this article. 
Funding: This research was funded by the National Natural Science Foundation of China under grant number 71774022.

Acknowledgments: We would like to thank Frank Boons at the University of Manchester for his valuable and constructive comments during the development of this article.

Conflicts of Interest: The authors declare no conflict of interest.

\section{References}

1. Liu, H.; Zhou, G.; Wennersten, R.; Frostell, B. Analysis of sustainable urban development approaches in China. Habitat Int. 2014, 41, 24-31. [CrossRef]

2. Chen, S. Environmental pollution emissions, regional productivity growth and ecological economic development in China. China Econ. Rev. 2015, 35, 171-182. [CrossRef]

3. Geng, Y.; Sarkis, J.; Ulgiati, S. Sustainability, wellbeing and the circular economy in China and worldwide. Science 2016, 120, 76-79.

4. State Council of China. The National Plan for New Urbanization (2014-2020); State Council of China: Beijing, China, 2014.

5. Central Leading Group for Comprehensively Deepening Reforms. Communique of the third Plenary Session of the 18th Central Committee of the Communist Party; Central Leading Group for Comprehensively Deepening Reforms: Beijing, China, 2014.

6. Wu, F. China's emergent city-region governance: A new form of state spatial selectivity through state-orchestrated rescaling. Int. J. Urban Reg. Res. 2017, 40, 1-18. [CrossRef]

7. Berardo, R.; Heikkila, T.; Gerlak, A.K. Interorganizational engagement in collaborative environmental management: Evidence from the South Florida Ecosystem Restoration Task Force. J. Public Adm. Res. Theory 2014, 24, 697-719. [CrossRef]

8. Negev, M. Interagency aspects of environmental policy: The case of environmental health. Environ. Policy Gov. 2016, 26, 205-219. [CrossRef]

9. Li, Y.; Wu, F. Understanding city-regionalism in China: Regional cooperation in the Yangtze River Delta. Reg. Stud. 2017, 52, 313-324. [CrossRef]

10. Li, Y.; Xu, J.; Yeh, A.G.O. State rescaling and the making of city-regions in the Pearl River Delta, China. Environ. Plan. C Gov. Policy 2014, 32, 129-143. [CrossRef]

11. Ansell, C.; Gash, A. Collaborative governance in theory and practice. J. Public Adm. Res. Theory 2008, 18, 543-571. [CrossRef]

12. Bryson, J.M.; Crosby, B.C.; Stone, M.M. The design and implementation of cross-sector collaborations: Propositions from the literature. Public Adm. Rev. 2006, 66 (Suppl. S1), 44-55. [CrossRef]

13. Emerson, K.; Nabatchi, T.; Balogh, S. An Integrative Framework for Collaborative Governance. J. Public Adm. Res. Theory 2012, 22, 1-29. [CrossRef]

14. Koppenjan, J. Creating a playing field for assessing the effectiveness of network collaboration by performance measures. Public Manag. Rev. 2008, 10, 699-714. [CrossRef]

15. Huxham, C.; Vangen, S. Managing to Collaborate: The Theory and Practice of Collaborative Advantage; Routledge: New York, NY, USA, 2013.

16. Spekkink, W.; Boons, F.A.A. The emergence of collaborations. J. Public Adm. Res. Theory 2016, 26, 613-630. [CrossRef]

17. Boons, F.A.A.; Spekkink, W.; Jiao, W. A Process Perspective on Industrial Symbiosis. J. Ind. Ecol. 2014, 18, 341-355. [CrossRef]

18. Lemos, M.C.; Agrawal, A. Environmental Governance. Annu. Rev. Environ. Res. 2006, 31, 297-325. [CrossRef]

19. Paavola, J. Institutions and environmental governance: A reconceptualization. Ecol. Econ. 2007, 63, 93-103. [CrossRef]

20. Ostrom, E. Metropolitan reform: Propositions derived from two traditions. Soc. Sci. Q. 1972, 53, 474-493.

21. Ostrom, E. Governing the Commons: The Evolution of Institutions for Collective Action; Cambridge University Press: Cambridge, UK, 1990.

22. North, D.C. Institutions. J. Econ. Perspect. 1991, 5, 97-112. [CrossRef]

23. McAllister, L.K. Environmental Enforcement and the Rule of Law in Brazil. Ph.D. Thesis, UC Berkeley, Berkeley, CA, USA, 2005. 
24. Weaver, R.K. Compliance regimes and barriers to behavioral change. Governance 2014, 27, 243-265. [CrossRef]

25. Lipsky, M. Street-Level Bureaucracy. Dilemmas of the Individual in the Public Services; Russell Sage Foundation: New York, NY, USA, 2010.

26. Wang, X.; Hawkins, C.V.; Lebredo, N.; Berman, E.M. Capacity to sustain sustainability: A study of US cities. Public Adm. Rev. 2012, 72, 841-853. [CrossRef]

27. Horton, D.; Alexaki, A.; Bennett-Lartey, S.; Kim, N.; Campilan, D. Evaluating Capacity Development: Experiences from Research and Development Organizations around the World; International Development Research Centre: Ottawa, ON, Canada, 2003.

28. Knoke, D.; Wright-Isak, C. Individual motives and organizational incentive systems. Res. Organ. 1982, 1 , 209-254.

29. Koppenjan, J.; Klijn, E.H. Managing Uncertainties in Networks: A Network Approach to Problem Solving and Decision Making; Routledge: London, UK, 2004.

30. Klijn, E.H.; Koppenjan, J. Governance Networks in the Public Sector; Routledge: London, UK, 2015.

31. Feiock, R.C. Metropolitan Governance: Conflict, Competition, and Cooperation; Georgetown University Press: Washington, DC, USA, 2004.

32. Feiock, R.C. Rational choice and regional governance. J. Urban Aff. 2007, 29, 47-63. [CrossRef]

33. Feiock, R.C. Metropolitan governance and institutional collective action. Urban Aff. Rev. 2009, 4, 356-377. [CrossRef]

34. Andrew, S.A. Recent developments in the study of interjurisdictional agreements: An overview and assessment. State Local Gov. Rev. 2009, 41, 133-142. [CrossRef]

35. Andrew, S.A.; Shout, J.E.; Jung, K.; Arlikatti, S. Intergovernmental cooperation in the provision of public safety: Monitoring mechanism embedded in interlocal agreements. Public Adm. Rev. 2015, 75, 401-410. [CrossRef]

36. Howlett, M. Designing Public Policies. Principles and Instruments; Routledge: London, UK, 2011.

37. Hills, P.; Man, C.S. Environmental Regulation and the Industrial Sector in China: The Role of Informal Relationships in Policy Implementation. Bus. Strategy Environ. 1998, 70, 53-70. [CrossRef]

38. Chisholm, D. Coordination without Hierarchy. Informal Structures in Multiorganizational Systems; University of California Press: Berkeley, CA, USA, 1989.

39. Putnam, R.D.; Leonardi, R.; Nanetti, R.Y. Making Democracy Work: Civic Traditions in Modern Italy; Princeton University Press: Princeton, NJ, USA, 1995.

40. LeRoux, K.; Brandenburger, P.W.; Pandey, S.K. Interlocal service cooperation in U.S. cities: A social network explanation. Public Adm. Rev. 2010, 70, 268-278. [CrossRef]

41. Coleman, J. Social capital in the creation of human capital. Am. J. Soc. 1988, 94, 95-120. [CrossRef]

42. Coleman, J. Foundations of Social Theory; Belknap Press: Cambridge, MA, USA, 1990.

43. Lin, N. Social Capital: A Theory of Social Structure and Action; Cambridge University Press: New York, NY, USA, 2001.

44. Esteve, M.; Boyne, G.; Sierra, V.; Ysa, T. Organizational collaboration in the public sector: Do chief executives make a difference? J. Public Adm. Res. Theory 2012, 23, 927-952. [CrossRef]

45. O'Leary, R.; Choi, Y.; Gerard, C.M. The skill set of the successful collaborator. Public Adm. Rev. 2012, 72, 70-83. [CrossRef]

46. Zhu, X. Mandate versus championship: Vertical government intervention and diffusion of innovation in public services in authoritarian China. Public Manag. Rev. 2014, 16, 117-139. [CrossRef]

47. Vatn, A. Environmental Governance. Institutions, Policies and Actions; Edward Elgar Publishing: Cheltenham, UK, 2015.

48. Ostrom, E.; Walker, J.; Gardner, R. Covenants with and without a sword: Self-governance is possible. Am. Political Sci. Rev. 1992, 86, 404-417. [CrossRef]

49. Amirkhanyan, A. Collaborative performance measurement: Examining and explaining the prevalence of collaboration in state and local government performance monitoring. J. Public Adm. Res. Theory 2009, 19, 523-554. [CrossRef]

50. Amirkhanyan, A. Monitoring across sectors: Examining the effect of nonprofit and for-profit contractor ownership on performance monitoring in state and local government contracts. Public Adm. Rev. 2010, 70, 742-755. [CrossRef] 
51. Keast, R.; Brown, K.; Mandell, M. Getting the right mix: Unpacking integration meanings and strategies. Int. Public Manag. J. 2007, 10, 9-33. [CrossRef]

52. Bardach, E.; Lesser, C. Accountability in human services collaboratives-For what? And to whom? J. Public Adm. Res. Theory 1996, 6, 197-224. [CrossRef]

53. Page, S. Entrepreneurial strategies for managing interagency collaboration. J. Public Adm. Res. Theory 2003, 13, 311-339. [CrossRef]

54. Whitaker, G.; Altman-Sauer, L.; Henderson, M. Mutual Accountability between Governments and Nonprofits: Moving beyond "Surveillance" to "Service". Am. Rev. Public Adm. 2004, 34, 115-133. [CrossRef]

55. Provan, K.G.; Kenis, P. Modes of network governance: Structure, management, and effectiveness. J. Public Adm. Res. Theory 2008, 18, 229-252. [CrossRef]

56. Abbott, A.; Tsay, A. Sequence analysis and optimal matching methods in sociology. Sociol. Methods Res. 2000, 29, 3-33. [CrossRef]

57. Abell, P. The Syntax of Social Life: The Theory and Methods of Comparative Narratives; Clarendon Press: Oxford, UK, 1987.

58. Poole, M.S.; van de Ven, A.H.; Dooley, K.; Holmes, M.E. Organizational Change and Innovation Processes: Theory and Methods for Research; Oxford University Press: New York, NY, USA, 2000.

59. Poole, M.S.; van de Ven, A.H. Handbook of Organizational Change and Innovation; Oxford University Press: New York, NY, USA, 2004.

60. Spekkink, W. Industrial Symbiosis as a Social Process. Ph.D. Thesis, Erasmus University Rotterdam, Rotterdam, The Netherlands, 2015.

61. Jiao, W.; Boons, F.A.A. Policy durability of Circular Economy in China: A process analysis of policy translation. Resour. Conserv. Recycl. 2017, 117 Pt A, 12-24. [CrossRef]

62. Boons, F.A.A.; Spekkink, W.A.H. Internalizing Environmental Responsibility in the Dutch Chemical Industry; Research Report; Dutch Scientific Council for Government Policy: The Hague, The Netherlands, 2015.

63. Yang, Z.; Cai, J.; Ottens, H.F.L.; Sliuzas, R. City profile: Beijing. Cities 2013, 31, 491-506. [CrossRef]

64. Wei, Y.D.; Jia, Y. The geographical foundations of local state initiatives: Globalizing Tianjin, China. Cities 2003, 20, 101-114. [CrossRef]

65. Chang, S.-D. Beijing: Perspectives on preservation, environment, and development. Cities 1998, 15, 13-25. [CrossRef]

66. Chang, S.-D.; Hu, X.; Sun, J. Tianjin: North China's reviving metropolis. In China's Costal Cities; Yeung, Y., Hu, X., Eds.; University of Hawaii Press: Honolulu, HI, USA, 1992; pp. 42-68.

67. Zhang, T. From intercity competition to collaborative planning. The case of the Yangtze River Delta Region of China. Urban Aff. Rev. 2006, 42, 26-56. [CrossRef]

68. Li, Y.; Wu, F. The emergence of centrally initiated regional plan in China: A case study of Yangtze River Delta Regional Plan. Habitat Int. 2013, 39, 137-147. [CrossRef]

69. Qi, Y.; Zhang, L. Local environmental enforcement constrained by central-local relations in China. Environ. Policy Gov. 2014, 24, 204-215. [CrossRef]

70. Yan, D.; Lei, Y.; Shi, Y.; Zhu, Q.; Li, L.; Zhang, Z. Evolution of the spatial temporal pattern of PM2.5 concentrations in China-A case study from the Beijing-Tianjin-Hebei region. Atmos. Environ. 2018, 183, 225-233. [CrossRef]

71. Balme, R.; Ye, Q. Multi-level governance and the environment: Intergovernmental relations and innovation in environmental policy. Environ. Policy Gov. 2014, 24, 147-154. [CrossRef]

72. Verweij, S.; Klijn, E.; Edelenbos, J.; Van Buuren, A. What Makes Governance Networks Work? A Fuzzy Set Qualitative Comparative Analysis of 14 Dutch Spatial Planning Projects. Public Adm. 2013, 91, 1035-1055. [CrossRef]

(C) 2018 by the authors. Licensee MDPI, Basel, Switzerland. This article is an open access article distributed under the terms and conditions of the Creative Commons Attribution (CC BY) license (http:/ / creativecommons.org/licenses/by/4.0/). 